ARTIGO

\title{
UTILIZAÇÃO DO ÍNDICE DE BULBO ÚMIDO E TERMÔMETRO DE GLOBO NO ENSINO DE TRANSFERÊNCIA DE CALOR PARA CURSOS DE GRADUAÇÃO NA ÁREA DE EXATAS ${ }^{1}$
}

\author{
Samuel Oliveira ${ }^{2}$
}

\section{RESUMO}

O presente trabalho tem como objetivo propor a utilização de um experimento técnico, conhecido como Índice de Bulbo Úmido e Termômetro de Globo (IBUTG), como material potencialmente significativo para aulas de Transferência de Calor em cursos de graduação na área de exatas, sendo sua metodologia de pesquisa baseada na teoria de aprendizagem de Ausubel e na metodologia por projetos, onde os resultados apontam que o experimento é um forte material experimental para o uso em sala de aula, tendo ele um conjunto de conceitos relevantes que possibilitam a sua conexão com a nova informação a ser aprendida e assim corroborando como forma substancialmente inovadora para o processo ensino aprendizagem.

Palavras-chave: Transferência de calor. IBUTG. Ensino de Física.

\section{INTRODUÇÃO}

O ensino de forma geral passa por transformações cujo objetivo principal é de qualificar e dinamizar a aprendizagem, e o envolvimento do estudante com objetos práticos e sua análise profunda, tem-se mostrado como um diferencial na aprendizagem dos mesmos. Assim, torna-se importante para a efetiva aprendizagem que o estudante esteja inserido no contexto acadêmico de forma que ele possa questionar as diferentes faces que estão por trás de um conceito e que assim o leve a pensar e questionar a respeito dos fenômenos físicos apresentados pelo professor através da teoria e também da utilização de experimentos relacionados.

A Termodinâmica, mais precisamente a Transferência de Calor, por ser uma disciplina com muitos conceitos e também, por possuir muitas leis e enunciados, necessita de uma abordagem mais contextualizada, sendo isso evidenciado no trabalho de Schneider et al. (2002) ao qual afirmam que os estudantes que utilizam de abordagem não tradicionais, ou

\footnotetext{
${ }^{1}$ Como citar este artigo: OLIVEIRA, Samuel. Utilização do índice de bulbo úmido e termômetro de globo no ensino de transferência de calor para cursos de graduação na área de exatas. ForScience: revista científica do IFMG, Formiga, v. 6, n. 3, e00435, jul./dez. 2018.
}

${ }^{2}$ Autor para correspondência: Samuel Oliveira, IFMG, e-mail: samuel.de.oliveira@ifmg.edu.br 
seja, aquelas que são trabalhadas por projetos ou então de forma contextualizada, obtém resultados melhores que estudantes que são ensinados pelo método tradicional de ensino.

Sabe-se que vários são os fatores aos quais os professores mantêm o estilo tradicional em sala de aula, estilo este em que o estudante é absorvedor de informação, alguns deles são: indisponibilidade de materiais práticos, formação precária do professor, resistência do professor em atualizar os conhecimentos, elaboração de aulas dinâmicas que seguem método eficazes de aprendizagem, etc.

Para agregar eficiência em aprendizagem, o autor analisa um caso prático de aplicação dos conceitos de Transferência de Calor, propondo-o como uma forma alternativa para o ensino da disciplina, visto que segundo Çengel e Guajar (2012) a transferência de calor é encontrada tanto em sistemas de engenharia como em outros aspectos da vida cotidiana, de forma que não é necessário ir tão distante ou profundo no assunto para ver suas aplicações, equipamentos de transferência de calor como trocadores de calor, condensadores, aquecedores, fornos são projetados principalmente a partir da análise de transferência de calor.

Desta forma, esse trabalho justifica-se pela sua importância acadêmica em promover uma formação atualizada a partir de materiais potencialmente significativos, auxiliando tanto professores quanto estudantes sobre o uso de recursos que contribuem pedagogicamente para a efetiva aprendizagem. Aliado a isso, o problema da pesquisa faz-se através da pergunta: Como formar estudantes capazes de compreender informações e criar relações práticas de forma que possam concluir e analisar os fenômenos físicos e tecnológicos que estão a sua volta e assim contribuir para o seu aprendizado?

\section{REFERENCIAL TEÓRICO}

\subsection{Métodos de aprendizagem}

Ao que se refere sobre teoria de aprendizagem, Moreira (2011) explica que ela é uma construção humana afim de interpretar e conhecer de forma sistemática a área de conhecimento ao qual denomina-se aprendizagem, sendo uma forma de dar significado e ao mesmo tempo entender ou até mesmo resolver problemas. Com base nesse seguimento, a teoria da aprendizagem significativa de Ausubel, mostra que o aprendizado terá eficiência quando novas informações vierem agregar conceitos e ideias já existentes na estrutura de 
conhecimento do estudante, e segundo Machado (2017) isso deve servir como um ancoradouro nas ideias pré-existentes do indivíduo, pois assim terá relevância para essa aprendizagem e tais aspectos devem ser bastante claros para que haja uma modificação ou progressão do novo conceito. Essa teoria vem contrastar com o modelo tradicional de ensino ao qual novas informações são apreendidas praticamente sem interação dos conceitos relevantes existentes na estrutura cognitiva, ou seja, sem ligar-se a conceitos específicos vivenciados no mundo do estudante.

De acordo com Lopes (2015) a aprendizagem significativa é aquela onde o significado do novo conhecimento é adquirido ou construído por meio da interação não-arbitrária e não literal desse novo conteúdo com outro já previamente existente, ou seja, a aprendizagem significativa é quando se vê o sentido nas situações de aprendizagem e dessa forma atribui-se significado a elas.

Diante disto, a teoria Ausubeliana parte do princípio que um material potencialmente significativo deve ser aquele cujas partes se relacionam com a experiência prévia do aluno de forma não arbitrária. Assim, para que o material tenha potencial e possa abrir a possibilidade de ser significativo, são necessários dois pré-requisitos: primeiro no que se refere a natureza do próprio material, ou seja, condutor de conhecimento e o segundo se refere à presença do conteúdo significativo na estrutura cognitiva do indivíduo que também dependerá da natureza do conhecimento prévio do aluno (LEMOS, 2012).

Tanto nas áreas sociais ou educacionais, Moura e Barbosa (2013) mostram que as atividades baseadas em projetos ocorrem em vários níveis e na área educacional são identificadas várias justificativas para o uso dessa metodologia, como por exemplo: reforma do sistema educacional, inclusão de novas tecnologias da educação, desenvolvimento do ensino, integração da escola com a comunidade, capacitação de professores e outras mais.

\subsection{Transferência de Calor}

Segundo Incropera et al. (2014) a importância da Transferência de Calor está no desenvolvimento e na avaliação na qual esse campo de estudo pode ser usado para resolver problemas relevantes para a tecnologia e para a sociedade. Ainda nesse contexto, Çengel e Guajar (2012) mostram que os problemas encontrados nesse assunto podem ser divididos em dois grupos: de avaliação e dimensionamento, sendo que os problemas de avaliação lidam com a determinação da taxa de transferência de calor de um sistema, enquanto que os 
problemas de dimensionamento tratam da determinação do tamanho do sistema e sua forma de transferir calor.

O calor é uma forma de energia térmica que pode ser transferida de um sistema para outro em consequência da diferença de temperatura entre eles, e assim a forma na qual esse calor é transmitido é feito de 3 maneiras distintas, cuja caracterização é feita a partir de modelos baseados nas leis de Fourier, de resfriamento de Newton e de Stefan Boltzmann; ao qual tratam respectivamente como condução, convecção e radiação. Deve-se ressaltar que em sistemas físicos reais essas três formas de propagação do calor podem estar presentes simultaneamente.

De acordo com Kreith, Manglik e Bohn (2010) a condução de calor ocorrerá sempre que houver um gradiente de temperatura em um meio sólido, e desta forma, o calor fluirá da região de maior temperatura para de menor temperatura, sendo essa taxa de transferência de calor descrita pela lei de Fourier, conforme equação (1)

$$
Q_{\text {cond }}=-k A \frac{d T}{d x}
$$

Essa equação é representada de forma unidimensional, onde $k$ representa a condutividade térmica do material, que em geral pode variar seu valor de acordo com a temperatura. Como explica Incropera et al. (2014), o sinal negativo na equação é consequência do calor ser transferido na direção da temperatura decrescente.

De acordo com Çengel e Guajar (2012) a convecção é um modo ao qual a transferência de calor entre uma superfície sólida e a líquida ou gás adjacente, envolve os efeitos combinados de condução e de movimento de um fluido. Esse fenômeno possui exemplos bem familiares como: sistema de refrigeração de motor de um automóvel, sistema de aquecimento de água residencial, fluxo de sangue pelo corpo, determinação das condições climáticas entre outros. Esta forma de transporte de energia térmica, apesar de sua complexidade, é convenientemente expressa como uma taxa na qual é dimensionada utilizando a lei de Newton do resfriamento, conforme mostra a equação (2)

$$
Q_{\text {conv }}=h A_{s}\left(T_{S}-T_{\infty}\right)
$$


Analisando a equação (2) o termo $h$ é denominado coeficiente de transferência de calor por convecção, podendo ser definido como a taxa de transferência de calor entre uma superfície sólida e um fluido por unidade de área e por unidade de diferença de temperatura. Apesar de simples, esse coeficiente depende de algumas variáveis, sendo, portanto de difícil determinação.

A transferência de calor por convecção é utilizada na vida diária com tamanha frequência que não é notada pela maioria das pessoas. Recorre-se a convecção sempre que se deseja aumentar a taxa de transferência de calor de um objeto quente, como por exemplo, ligar o ventilador em dias quentes de verão para aliviar a sensação térmica sofrida por uma pessoa. O mesmo pode ser explicado com o ar em um dia de vento, numa estação de inverno, ele parece ser mais frio do que realmente é.

A terceira forma na qual o calor pode se propagar é determinada pela radiação. Ela difere dos outros dois mecanismos citados anteriormente no que se refere a presença de um meio material, sendo sua ocorrência em sólidos, líquidos e gases. A radiação térmica é o resultado das transições de energia de moléculas, átomos e elétrons de uma substância, sendo ela continuamente emitida por todas as matérias cuja temperatura é superior ao zero absoluto, ou seja, tudo emite radiação.

A taxa pela qual uma superfície emite radiação térmica, pode ser calculada segundo Çengel e Guajar (2012) pela lei de Stefan-Boltzmann, dada pela equação (3)

$$
Q_{\text {rad }}=\varepsilon \sigma A_{S}\left(T_{S}^{4}-T_{v i z}^{4}\right)
$$

Nessa equação, $\varepsilon$ representa a emissividade da superfície, uma grandeza adimensional e $\sigma$ é a constante de Stefan-Boltzmann, dada por $5,670.10^{-8}\left(\mathrm{~W} / \mathrm{m}^{2} . \mathrm{K}\right)$. Com base nesta equação podese mensurar a perda de calor obtida por radiação de uma pessoa em pé num ambiente fechado, que em média chega a $81,7 \mathrm{~W}$.

\subsection{Conforto térmico e IBUTG}

Segundo Oliveira e Costa (2014), o estudo sobre o conforto térmico está associado a questão em estabelecer critérios de condições ideais de um ambiente termicamente confortável, de forma a acarretar comodidade e satisfação as pessoas que nele estão inseridas. Por isso o estudo em conforto térmico tende a mensurar a eficiência do trabalho, seja ele intelectual ou braçal, pois a performance humana dentro de certas atividades executadas 
possui influência direta na sensação de bem-estar, com isso, ganhar ou perder calor pode provocar desconforto e reduzir o desempenho humano, influenciando nas atividades intelectuais, manuais e perceptivas.

Para Çengel e Guajar (2012) o conforto humano depende de três fatores ambientais: a temperatura do ambiente, a umidade relativa do ambiente e o movimento causado pelo ar. A temperatura do ambiente é um dos mais importantes índices de conforto térmico, tendo em vista que várias pesquisas têm sido feitas para determinar uma zona de conforto térmico para o homem. No Brasil, tais pesquisas relacionadas sobre o assunto se inserem numa área recente e não há muitos dados pertinentes ao tema, sendo necessário então utilizar parâmetros estabelecidos em outros países.

O Índice de Bulbo Úmido Termômetro de Globo (IBUTG) segundo Oliveira e Costa (2014) foi desenvolvido com o objetivo de avaliar a condição de sobrecarga para um grupo específico de atividades, ao qual a partir dessa avaliação é possível obter uma forma de calcular um melhor tempo de descanso nessas atividades. Sakoi et al. (2018) mostra que o índice IBUTG foi proposto em 1957 por Yaglou e Minard com o intuito de evitar que indivíduos venham a sofrer de algum mal relacionado a carga térmica recebida em centro militares de treinamento. Pela simplicidade analítica desse índice ele torna-se um ótimo indicador para aplicação em qualquer local de trabalho.

Para determiná-lo, é necessário um conjunto de instrumentos que são: termômetro de globo, termômetro de bulbo úmido e termômetro de bulbo seco. A Figura 1 a seguir, mostra como são os termômetros de bulbo úmido e de globo.

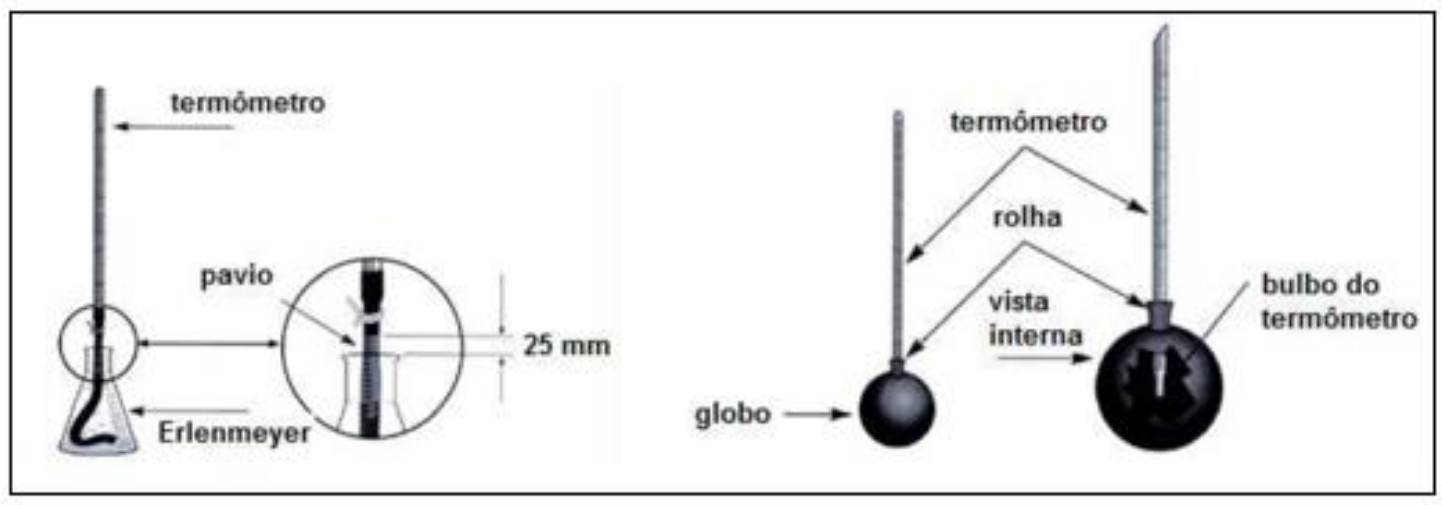

Figura 1 - Termômetro de bulbo úmido e termômetro de globo Fonte: Brasil (2002). 
O IBUTG leva em consideração os fatores ambientais e fisiológicos que favorecem o equilíbrio homeotérmico e é utilizado pela American Conference of Governmental Industrial Hygienists (ACGIH), National Institute for Occupational Safetyand Health (NIOSH) e também pela Norma Regulamentadora (NR-15). Em Brasil (2015) são definidas as formas na qual o IBUTG é calculado, relatando a existência de duas equações para o cálculo desse índice, a equação (4) refere-se a ambientes no qual não há incidência direta de carga solar, podendo ser ambientes internos ou externos:

$$
I B U T G=0,7 t b n+0,3 t g
$$

Já a equação (5) calcula o índice de forma que o ambiente seja externo e com a presença direta de carga solar sobre o indivíduo:

$$
I B U T G=0,7 t b n+0,1 t b s+0,2 t g
$$

Para essas duas equações tem-se que o significado de tbn é a temperatura de bulbo úmido natural, $t g$ faz referência à temperatura de globo e $t b s$ a temperatura de bulbo seco. De acordo com o autor supracitado, os equipamentos que devem ser utilizados nesta avaliação são termômetro de bulbo úmido natural, termômetro de globo e termômetro de mercúrio comum, no qual as medições devem ser efetuadas no local onde permanece o indivíduo, à uma altura da região do corpo mais atingida.

\section{METODOLOGIA}

\subsection{Preparação da pesquisa}

Dentre inúmeras metodologias de ensino, o autor escolheu para essa análise a teoria de aprendizagem de Ausubel, concomitante a metodologia por projetos que de acordo com Berehns (2014) auxilia no crescimento da visão interdisciplinar, pois representa um processo metodológico de aprendizagem que envolve níveis de integração, interconexão, interrelacionamento de informações, associação de informações, conteúdos, conhecimentos e saberes na busca de uma abordagem mais complexa. Assim, o presente trabalho analisa uma forma pela qual a aprendizagem seja significativa, de forma a substituir o método tradicional de ensino, utilizando um material potencialmente significativo, sendo a pesquisa realizada 
com base em textos e artigos científicos da área. Para isso, o tema central proposto, Transferência de Calor, constitui uma opção para que a análise seja mais efetiva e conclusiva acerca de um tema presente nos cursos da área de exatas, possibilitando que os professores e estudantes analisem e apliquem essa abordagem na construção do conhecimento científico de forma efetiva.

A pesquisa realizada é de caráter bibliográfica, onde segundo Severino (2016) é aquela na qual é realizada a partir de documentos decorrentes de pesquisas anteriores, utilizando-se de dados teóricos ou não, já trabalhados por outros pesquisadores. Por isso, a presente pesquisa analisa a aplicação de uma prática experimental, que pode ser utilizada na disciplina de Transferência de Calor.

\subsection{Preparação do material}

Para a montagem do experimento foi utilizado como referência o trabalho de Oliveira e Costa (2014), que aplicaram o índice IBUTG no ambiente acadêmico, a fim de obter quais as condições de conforto térmico existentes naquele ambiente. A sugestão da aplicação desse experimento como um material potencialmente significativo, implica no favorecimento efetivo da aprendizagem significativa, cumprindo as etapas sugeridas por David Ausubel, que trata-se de selecionar, organizar e elaborar um material educativo e ao mesmo tempo verificar se esse material corresponde ao contexto da disciplina e evidencia os conceitos a serem ensinado de uma nova maneira.

Para a montagem desse experimento, são utilizados três componentes ao qual é relatado a seguir: o primeiro trata-se do termômetro de globo, ao qual é composto por uma esfera oca de cobre com 1,0 mm de espessura, tendo um diâmetro de 152,4 mm na cor preta. Essa esfera possui uma abertura radial que é completada por um cilindro de 25,0 $\mathrm{mm}$ de comprimento e 18,0 mm de diâmetro, local ao qual será instalado o termômetro de mercúrio. A escala do termômetro de mercúrio varia de $+10^{\circ} \mathrm{C}$ a $+120^{\circ} \mathrm{C}$, tendo uma precisão de \pm $0,5^{\circ} \mathrm{C}$, e há também uma rolha de borracha na cor preta com diâmetro superior a $20,0 \mathrm{~mm}$ e diâmetro inferior a 15,0 $\mathrm{mm}$ e sua altura está entre $20,0 \mathrm{~mm}$ a 25,0 $\mathrm{mm}$, a mesma é vazada no centro, pois, o termômetro será fixado na esfera por meio dela. O segundo componente do experimento é o termômetro de bulbo úmido, que tem como função, medir a umidade do ar, sendo constituído por um termômetro de mercúrio que varia de uma escala de $+10,0{ }^{\circ} \mathrm{C}$ a $+50,0{ }^{\circ} \mathrm{C}$ com uma precisão de $\pm 0,5^{\circ} \mathrm{C}$, e que contém um erlenmeyer de $125,0 \mathrm{ml}$ com água 
destilada. Nesse conjunto será instalado um pavio de algodão que serve para absorver a água, cujo comprimento deverá ser de aproximadamente 100,0 mm. Por fim, o último equipamento que compõe o tripé IBUTG é o termômetro de bulbo seco, ao qual destina-separa obter a temperatura do ar, e sua escala varia de $+10,0{ }^{\circ} \mathrm{C}$ a $+100,0{ }^{\circ} \mathrm{C}$ com precisão de $\pm 0,5^{\circ} \mathrm{C}$. A seguir, na Figura 2, tem-se a representação do tripé envolvendo todos os equipamentos.

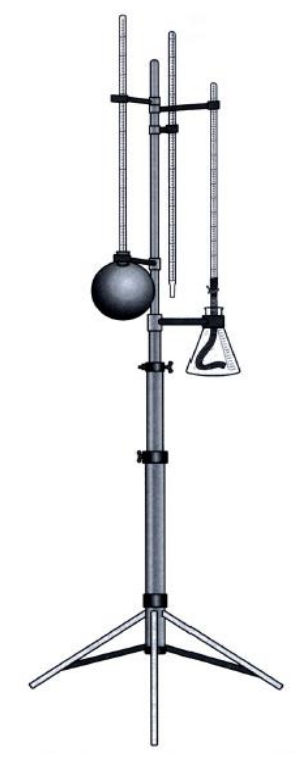

Figura 2 - Tripé IBUTG Fonte: NHO 06 (2017).

\section{RESULTADOS E ANÁLISE}

Como ponto de partida ao uso do IBUTG como material potencialmente significativo, o professor ao adotar esse experimento de forma pedagógica, pode considerar três momentos distintos para a aplicação do mesmo: introdução dos equipamentos, desenvolvimento da sua aplicação e explicação do resultado atrelado ao fenômeno da Transferência de Calor.

É importante ressaltar que a utilização desse método não deve ser utilizada como uma simples demonstração, de forma que ele próprio se explique. A aprendizagem significativa ao qual se espera pode ser pouco eficiente, caso o material seja apenas mostrado, pois, os estudantes podem não observar a relação existente entre a disciplina e o experimento. É necessário descrever o equipamento e mostrar quais são seus aspectos relevantes e, principalmente, o que deve ser observado durante a demonstração. Por isso, deve-se abordar as diferentes definições acerca dos conceitos de calor, condução, convecção, radiação, ao qual só será possível com uma discussão prévia a respeito da própria utilização do experimento. 
Por isso que Oliveira (2016) afirma que no intuito de aprofundar e caracterizar o ensino de Física como uma ferramenta para o conhecimento, deve-se buscar uma aprendizagem significativa a partir do momento em que seus conceitos intermediários também são assimilados por meio dos conceitos preexistentes e não apenas no uso de fórmulas prontas para sua execução e para que o IBUTG adquira a característica de material potencialmente significativo, ele precisa ter uma relação entre a natureza do conhecimento do aluno e do conteúdo a ser ensinado. Por isso, diante da avaliação realizada pelo autor da pesquisa, verificou-se que o entendimento e análise de cada equipamento constituinte do tripé IBUTG antes da efetiva aplicação prática, estabelece-se como um subsunçor para a aprendizagem significativa. Para o primeiro componente citado, o termômetro de globo, em sua montagem o professor abordará e explicará a relação da transferência de calor por radiação, englobando suas principais características e dando ênfase ao estudo da radiação do corpo negro. Com isso, é sugerido que os alunos comprovem cada medida que descreve esse equipamento.

Para o segundo componente, o termômetro de bulbo úmido, o professor abordará e descreverá as principais características do modo de transferência de calor por convecção, aproveitando que nesse modo de transferência, é necessário que o meio ao qual está sendo analisado, deve ser um meio fluido. Ainda nessa parte, aproveita-se para incluir as considerações sobre a vestimenta das pessoas que estarão presentes no ambiente do experimento, relatando como funciona o isolamento térmico nas trocas de calor por convecção e radiação.

Após a descrição de cada componente que compõe o experimento, acredita-se que a sua utilização em sala de aula promoverá no aluno a construção efetiva da aprendizagem em relação ao tema proposto pelo autor. Tanto do ponto de vista cognitivo quanto prático, essa metodologia focada na teoria de Ausubel, indica que essa atividade pode ser pedagogicamente válida e significativa, mas para que isso ocorra, é essencial que o professor se adeque e faça uma análise efetiva sobre como ensinar os conceitos, utilizando o material e com uma fundamentação teórico-pedagógica adequada que justifique sua validade e oriente sua estruturação e desenvolvimento no ambiente de ensino. Trabalhos como esse, valorizam o processo de ensino e aprendizagem, enfatizando um caráter motivacional, ao qual torna-se um aspecto importante para a aprendizagem. Diante disto, verifica-se, conforme cita Moreira (2011), que a teoria de aprendizagem de Ausubel implica no processo ao qual se dá a efetiva estrutura cognitiva, sendo ela empregada em métodos adequados de apresentação do conteúdo 
e utilização de princípios programáticos apropriados na organização sequencial da matéria de ensino.

A comunidade docente brasileira já possui uma preocupação recorrente sobre o ensino de Física de uma forma geral. Vários são os artigos e textos relatando sua preocupação com este item, e apesar de um número grande de pesquisas sobre essa área, pouco se tem chegado efetivamente ao seu ponto final, que seria a sala de aula. O que se pode relatar é que vários são os trabalhos realizados, mas poucos são aqueles implementados ou até então com real aprendizagem para o aluno.

O método tradicional ainda prevalece sobre os grandes centros de ensino, seja ele público ou particular e de acordo com Seabra (2017) é necessário a exploração de abordagens atualizadas em sala de aula no sentido de evidenciar aos estudantes as inúmeras possiblidades de atuação e consequente potencial para melhorias das tecnologias existentes.

É importante relatar que existe uma lacuna entre a pesquisa no ensino de Física e a entrega de seus resultados para livros textos e consequentemente para a sala de aula. $\mathrm{O}$ que se deve ter em prática é que a assimilação de novos métodos precisa ter o seu ponto final na inserção do estudante com a vivência prática da realidade ao qual ele vive.

As diversas pesquisas sobre o ensino, mostram que ainda há prevalência do modelo tradicional, onde o professor transmite um conteúdo e por seguinte é cobrado do aluno por meio de exercícios teóricos uma assimilação do mesmo, o que pode acarretar numa aprendizagem abstrata e talvez errônea. Outra dificuldade é a resistência de professores quanto a atualização de seus métodos para atuar conforme a perspectivas das novas metodologias de ensino. Dessa forma, vários autores e também vários professores, com foco no modelo tradicional de ensino, ao lecionarem a disciplina Transferência de Calor, partem primeiro do tema condução de calor, isoladamente, mostrando suas equações e suas análises teóricas e por sequência abordam o tema convecção e radiação.

Essa introdução dos principais temas da disciplina leva a crer que o aluno, por alguma experiência vivida anteriormente possa assimilar seus conceitos, mas sem o uso de materiais potencialmente significativos, a aprendizagem significativa poderá não ocorrer, levando o aluno a simplesmente memorizar aquilo que lhe foi passado com o intuito apenas de ser aprovado em exames avaliativos. Com a utilização da prática experimental, o estudante será levado a uma investigação mais profunda dos fenômenos de troca de calor e ao mesmo tempo, poderá confrontar o experimento com a teoria já aprendida, e assim, a aprendizagem 
significativa se tornará efetiva, criando uma sintonia entre aquilo que ele tem como experiência de vida na busca pela absorção do conhecimento.

\title{
5 CONCLUSÃO
}

Esta pesquisa, além de verificar a validade das informações acerca de métodos de aprendizagem em sala de aula, permitiu também sugerir um experimento com intuito de agregar substancialmente formas inovadoras para que o processo ensino-aprendizagem tornese efetivo, da mesma forma, que a metodologia por projetos, oferece alternativa para que um experimento técnico possa ser utilizado em sala de aula, tendo o professor como agente fundamental do processo.

Assim, conclui-se que uma situação prática com foco na aprendizagem significativa viabiliza uma interação técnica-pedagógica, motivando e envolvendo o estudante por meio de interpretação e até mesmo pelo impacto do próprio experimento.

\section{UTILIZATION OF THE WET BULB GLOBE TEMPERATURE, WBGT, IN TEACHING OF THE HEAT TRANSFER FOR GRADUATION COURSES IN EXACT SCIENCES}

\begin{abstract}
This paper has the objective propose the use of a technical experiment known as Wet-bulb globe temperature, WBGT, as potentially significant material for Heat Transfer classes in undergraduate courses in exact sciences, and its research methodology based on Ausubel learning theory and methodology for projects. The results show that the experiment is a strong experimental material for use in the classroom, having a set of relevant concepts that enable its connection with the new information to be learned and substantially corroborating the innovative path to the teaching learning process.
\end{abstract}

Keywords: Heat transfer. WBGT. Physics teaching.

\section{REFERÊNCIAS}

BEHRENS, M. A. Metodologia de projetos: aprender e ensinar para a produção do conhecimento numa visão complexa. 2014. p. 95-116. Disponível em:

<http://www.agrinho.com.br/site/wp-content/uploads/2014/09/2_04_Metodologia-deprojetos.pdf/> Acesso em: 23 jan. 2017.

BRASIL. Ministério do Trabalho. Norma de higiene ocupacional 06: procedimentos técnicos: avaliação da exposição ocupacional ao calor. Brasília, 2002. 
BRASIL. Ministério do Trabalho e Emprego. NR 15 - Atividades e Operações Insalubre. Brasília, 2015. Disponível em: < http://trabalho.gov.br/seguranca-e-saude-notrabalho/normatizacao/normas-regulamentadoras/norma-regulamentadora-n-15-atividades-eoperacoes-insalubres>. Acesso em: 13 dez. 2017.

ÇENGEL, Y. A.; GUAJAR, A. J. Transferência de calor e massa: uma abordagem prática. 4. ed. Porto Alegre: AMGH, 2012. 904 p.

INCROPERA, F. P. et al. Fundamentos de transferência de calor e massa. 7. ed. Rio de Janeiro: LTC, 2014. 694 p.

KREITH, F.; MANGLIK, R. M.; BOHN, M. S. Princípios da transferência de calor. 7. ed. São Paulo: Cengage Learning, 2010. 676 p.

LEMOS, E. S. Enseñanza y elhacer docente: reflexiones a la luz de la teoria del aprendizaje significativo. Aprendizagem significativa em revista. Campus do Vale, v. 2, n. 2, p. 23-41, 2012.

LOPES, V. Análise de um objeto de aprendizagem na perspectiva da teoria da aprendizagem significativa: o professor diante da possibilidade de transformação. ForScience: revista científica do IFMG, Formiga, v. 3, n. 1, p. 87-103, jan./jun. 2015.

MACHADO, C. T. Mapas conceituais como instrumento de avaliação em estudos de termodinâmica no ensino médio. 2017. 87 f. Dissertação (Mestrado profissional em ensino de Física) - Instituto de Física, Universidade de Brasília, Brasília, 2017.

MOREIRA, M. A. Teorias de Aprendizagem. 2. ed. São Paulo: EPU, 2011. 248 p.

MOURA, D. G.; BARBOSA, E. F. Trabalhando com projetos: planejamento e gestão de projetos educacionais. 8. ed. Petrópolis: Vozes, 2013.

NORMA DE HIGIENE OCUPACIONAL 06 (NHO-06): avaliação da exposição ocupacional ao calor. 2. ed. São Paulo: Fundacentro, 2017.

OLIVEIRA, S. Uma releitura sobre a abordagem da Lei de Coulomb e da Lei de Gauss no Ensino de Física para os cursos de Engenharia. Revista Conexão Ciência, Formiga, v. 11, n. 2, p. 110-118, 2016.

OLIVEIRA, S.; COSTA, C. S. Análise do conforto térmico em uma sala de aula. Revista Conexão Ciência, Formiga, v. 9, n. 1, p. 74-84, 2014.

SAKOI, T. et al. Heat balance model for ahumanbody in theformofwetbulbglobe temperature índices. Journal of thermal biology, v. 71, p. 1-9, 2018. 
SCHNEIDER, R. M. et al. Students in Project-Based Science Classroomson a National Measureof Science Achievement. Journal of research in science teaching, v. 39, n. 5, p. 410-422, 2002.

SEABRA, R. D. Uma abordagem no ensino da disciplina de informática e sociedade em um curso de ciências da computação: o relato de uma experiência. ForScience: revista científica do IFMG, Formiga, v. 5, n. 1, p. 1-18, jan./jun. 2017.

SEVERINO, A. J. Metodologia do trabalho científico. 24. ed. São Paulo: Cortez, 2016. 320 p.

\section{DADOS DO AUTOR}

\section{Samuel Oliveira}

E-mail: samuel.de.oliveira@ifmg.edu.br

Currículo lattes: lattes.cnpq.br/9834545025638255

Especialista em ensino de Física e Mestre em Engenharia pela Universidade Federal de Lavras (UFLA-MG). 